\title{
Coherence-Driven Constraints on the Placement of Accent
}

\author{
Andrew Kehler \\ University of California, San Diego
}

\section{Introduction}

It is well-established that there is a correspondence between the discourse status of information (i.e., given or new) on the one hand, and whether the linguistic material that denotes that information receives accent or not. It is equally well-established, however, that this correspondence is not straightforward. For instance, sometimes linguistic material that represents new information is not accented, as in the case of went in (1):
a. $\{$ What did John do? $\}$
b. He [went to the MOVIES] .

Here, the accent on movies appears to not only mark its denotation as new, but that of the entire verb phrase that contains it (notated with the subscript $F$ ). On the other hand, sometimes material that denotes old information receives accent:
a. $\left\{\right.$ Who did $\mathrm{John}_{j}$ 's mother praise? $\}$
b. She praised $\left[\mathrm{HIM}_{j}\right]_{F}$.
(Schwarzschild (1999), ex. 11)

The pronoun him in (2) represents given information, but nonetheless receives accent in order to mark a larger constituent that contains it as new.

While there has been much written on these matters - indeed many works that are directly relevant to the study reported on here - I will focus particularly on Schwarzschild's (1999) attractive analysis, in which a wide range of accent patterns fall out from an optimization-driven interaction among a small set of rules and violable constraints. One of the great strengths of the theory is that it offers a single mechanism that simultaneously captures the different ways in which new information has been defined in the literature, including "textually and situationally non-derivable information", "contrary to some predicted or stated alternative", and "replacing the WH-element in a presupposed question" (Halliday 1967). The first of these notions addresses the question of why praised receives accent in (3) whereas him does not. The second and third definitions are needed for examples (4) and (2) respectively; in each case a word representing given information receives accent.
a. $\{$ What did John's mother do?

b. She $\left[[\mathrm{PRAISED}]_{F} \mathrm{him}_{F}\right.$.

(Schwarzshild's ex. 9) 
a. \{John's mother voted for Bill. $\}$

b. No, she voted for $\mathrm{JOHN}_{F}$. (Schwarzshild's ex. 2)

A central component of Schwarzschild's theory is a constraint, AVOIDF, that economizes on focus marking (or $F$-marking). In this paper I will argue that no general constraint of this type determines accent placement in English, and further that felicitous accent patterns are in part determined by factors that lie outside of his system. I focus particularly on how the COHERENCE RELATION that the speaker intends the hearer to recognize among utterances influences how they are partitioned with respect to background and focus, which in turn influences accent placement. These differences explain why Schwarzschild's theory successfully predicts that the accent pattern in (5a) is felicitous as opposed to the one in $(5 \mathrm{~b})$, but at the same time why the opposite accent pattern is evidenced in (6), counter to the preferences imposed by AVOIDF:

(5) \{ John cited Mary, but $\}$

a. he DISSED $F$ SUE $_{F}$.

b. \# he [dissed $\left.\operatorname{SUE}_{F}\right]_{F}$. (Schwarzschild's ex. 60)

(6) $\{$ Fred read the menu and then

a. \# he ORDERED $F$ [a HAMBURGER $]_{F}$.

b. he $\left[\operatorname{ordered}_{F}[\text { a HAMBURGER }]_{F}\right]_{F}$.

In the next section I briefly describe Schwarzschild's system and an objection to his account due to Krifka that, while I believe to be in error, is instructive to consider. In section 3, I discuss a variety of examples that do pose a problem for the analysis. In section 4, I offer a revision to Schwarzschild's system, and describe how it makes different predictions for the accent patterns one finds between coherence relations that are based on establishing parallelism or contrast (5) and those that are not (6). I then follow with a brief discussion of Question-Under-Discussion models (Roberts 1996, Büring 2003) in section 5, and a note about gapping in section 6 . I conclude in section 7.

\section{Schwarzschild's Analysis}

I begin with a brief description of Schwarzschild's system. In his analysis, felicitous utterances are entailed by the prior discourse (that is, GIVEN). Since a speaker will presumably want to express information that is in fact not so entailed, she is entrusted with a tool -F-marking - as long as she agrees to use it as economically as possible. F-marking a phrase effectively turns it into a 'wildcard' (or 'F-variable') for the purpose of establishing Givenness. An utterance's F-marking will then in part determine the manner in which she distributes accent within it. 
The fact that only propositions can be entailed gives rise to an immediate problem, since we wish to evaluate the Givenness status of information of all semantic types. To remedy this, Schwarzschild employs a mechanism of EXISTENTIAL TYPE SHIFTING, in which expressions are raised to type $t$ by existentially binding unfilled arguments. This process, for instance, will convert the denotation of the VP ate an apple to the proposition $\exists X$.[Xate an apple]. With this tool in hand, the EXISTENTIAL F-CLOSURE of an utterance $U$ is defined as follows:

Existential F-closure of $U$ : the result of replacing F-marked phrases in $U$ with variables and existentially closing the result, modulo existential type shifting.

Givenness is then defined in terms of coreference (for entities) and entailment of Existential F-closures (for other types):

Given (final informal version):

An utterance $U$ counts as GIVEN iff it has a salient antecedent $A$ and

a. if $\mathrm{U}$ is type $e$, then $\mathrm{A}$ and $\mathrm{U}$ corefer;

b. otherwise: modulo E-type shifting, A entails the Existential F-Closure of U.

Crucially, F-marking a constituent does not entail that it will receive accent. Indeed, only those constituents that are not immediately dominated by another F-marked constituent require one; these are called Foc-marked nodes:

Foc-marking: A Foc-marked node is an F-marked node that is not immediately dominated by another F-marked node.

Finally, Schwarzschild adopts Selkirk's (1996) BASIC FOCUS RULE which requires F-marking on an accented word:

Basic Focus Rule: An accented word is F-marked.

With these definitions in hand, Schwarzschild's system is defined by the following four constraints:

GIVENness: A constituent that is not F-marked is given.

AVOIDF: Do not F-mark.

FOC: A Foc-marked phrase contains an accent.

HEADARG: A head is less prominent that its internal argument.

These constraints participate in the following Optimality Theoretic style rankings:

GIVENness $>>$ AVOIDF

FOC $>>$ AVOIDF

AVOIDF $>>$ HEADARG

The predicted F-marking and accent pattern for an utterance is the one that is optimal in light of this ranking and the (indef easible) Basic Focus Rule.

Let us make Schwarzschild's system more concrete by working through two of his examples that are particularly relevant to my purposes, starting with (7): 
a. $\{$ What did John's mother do? $\}$ She $\left[[\mathrm{PRAISED}]_{F} \text { him }\right]_{F}$.

b. $\exists R\left[\right.$ She $_{m} R$-ed $]$

In this case, praised is new and must be F-marked in light of GIVENNESS. The other two words (she and her) are Given, and hence need no F-marking. The VP praised $_{F}$ him is also new and thus must be F-marked, since nothing entails its Existential F-closure (i.e., that something happened to John). The whole sentence is not F-marked, since the (7a) entails its Existential F-closure (shown in (7b), i.e., that John's mother did something). The VP is FOC-marked because it is not dominated by another F-marked constituent, and thus by FoC must receive an accent. HEADARG would prefer an accent on him, but the Basic Focus Rule would then require that it be F-marked (where it was not already), incurring a violation of AVOIDF. Accent on praised violates HEADARG, but does not require a new Fmarker. Since AVOIDF outranks HEADARG, the accent goes on praised, which is the correct prediction.

Let us now consider (5), repeated below as (8):

a. $\{$ John cited Mary, $\}$ but he $\operatorname{DISSED}_{F} \operatorname{SUE}_{F}$.

b. $\exists R \exists Y\left[\mathrm{He}_{j} R\right.$-ed $\left.Y\right]$

The referent of he, John, is Given. The other two words, dissed and Sue, are new, and hence must be F-marked. This F-marking gives rise to the Existential F-Closure in (8b), i.e., that John did something to somebody. Since (8b) is entailed by (8a), no further F-marking need be, and thus by AvoIDF can be, added. Since neither F-marked constituent is dominated by another F-marked constituent, by Foc both receive accent. Note therefore that economy of F-marking does not entail economy of accent: If an additional F-marker were included at the VP level, only Sue would require accent (cf. (6)).

In sum, Schwarzschild's system captures the felicitous accent patterns in both (7) and (8), as well as in a variety of others that he discusses. As we already saw in the introduction, however, examples such as (6) which license the Existential F-closure in (8b) do not give rise to the accent pattern in (8a). I return to this point in section 3 .

\subsection{Krifka's Objection}

Krifka (2004) presents data to refute Schwarzschild's analysis. I believe his criticisms are incorrect, and it serves our current purposes to understand why. Krifka presents the question and two possible answers in (9):

What did John do?

(Krifka's ex. 29)
a. He $\left[\operatorname{read}_{F} \mathrm{ULYSSES}_{F}\right]_{F}$.
b. \# He READ ULYSSES $_{F}$. 
Krifka claims that the question in (9) entails the Existential F-closure of (9b), and hence the accent pattern in (9b) should be preferred to that in (9a). However, this entailment relation does not actually hold in Schwarzschild's system: While the question entails that John did something, it does not entail that John did something to something, that is, there is no transitive relation made Given by the question. As such, (9a) is the appropriate F-marking. This case can be contrasted directly with another one of Krifka's:

(10) What did John do with which novel?

(Krifka's ex. 20)

a. \# He $\left[\operatorname{read}_{F} \mathrm{ULYSSES}_{F}\right]_{F}$.

b. He READ ULYSSES $_{F}$ (and CRITICIZED $F$ [FINNEGAN'S WAKE] $]_{F}$ ).

Here the question does entail the Existential F-closure corresponding to John did something to something, and Schwarzschild's analysis therefore correctly predicts the focus and accent pattern shown in (10b).

\section{The Influence of Coherence}

Although Schwarzschild's system captures the inherent contrast between (9) and (10), other examples show that the question of whether to build an Existential FClosure around a Given transitive relation or an intransitive one is not always clear cut. In this section I present a set of minimal pairs which differ with respect to the COHERENCE RELATION that the speaker intends the hearer to construe between the clauses. The felicity of accent patterns will be shown to depend specifically on whether the relation is in the RESEMBLANCE category (Kehler 2002), which includes relations such as PARALLEL and CONTRAST (among others), or one that is not, including CAUSE-EFFECT relations (e.g., RESULT) and CONTIGUITY relations (e.g., OCCASION). In each case Schwarzschild's analysis makes the same predictions for both members of the minimal pair, whereas in actuality different accent patterns are attested for them.

Let us begin by considering a single passage that is ambiguous between Parallel and Result construals, given in (11):

(11) Powell defied Cheney, and Bush punished him.

(Kehler 2002)

The Parallel construal is based on establishing points of similarity and contrast among sets of corresponding entities and relations. On this reading, and can be paraphrased as and similarly, as if the passage were answering the question who did what to whom?. On the other hand, the Result construal is characterized by a cause-and-effect interpretation between the clauses, in which and can be paraphrased as and as a result. In this case the coherence is based not on similarity and contrast, but instead the world knowledge that people who defy others may get punished for it. 
The accent patterns that accompany these two construals are different. In the Parallel case, the pronoun him is unaccented if it refers to Cheney, and must be accented if it refers to Powell. These accent patterns and corresponding F-markings are shown in (12).
a. $\mathrm{BUSH}_{F}$ PUNISHED $_{F}$ him.
(him=Cheney)
b. $\mathrm{BUSH}_{F}$ PUNISHED $_{F} \mathrm{HIM}_{F}$.
(HIM=Powell)

On the other hand, him requires no accent to if it is to be interpreted as referring to Powell on the relevant Result interpretation. Indeed, accenting him in this case has an interpretation in which it refers to Cheney, signaling the violation of an expectation about who would be punished. These accent patterns and corresponding F-markings are shown in (13).
a. $\mathrm{BUSH}_{F}\left[\mathrm{PUNISHED}_{F} \text { him }\right]_{F}$
(him=Powell)
b. $\mathrm{BUSH}_{F}$ punished $\mathrm{HIM}_{F}$.
(him=Cheney)

It is worth noting that these accent patterns are independent of the choice to pronominalize the object of the second clause; the same accent patterns result with the remention of a proper name. For the time being, let us in fact consider only the case in which Powell is the person getting punished. In Schwarzschild's system there are two competing F-markings at play: (14a) is analogous to that for (8) and (14b) is analogous to that for (7), modulo the fact that the subject in this case is new:
a. $\mathrm{BUSH}_{F} \mathrm{PUNISHED}_{F}$ POWELL $_{F}$. (Parallel)
b. $\mathrm{BUSH}_{F}\left[\right.$ PUNISHED $_{F}$ Powell $_{F}$. (Result)

Either F-marking is licensed, since Powell defied Cheney entails both that Someone did something (needed for (14b)) and that Someone did something to someone (needed for (14a)).

Schwarzschild does not give a precise metric on F-marking that would distinguish these cases. While both involve three F-marks, a case could be made that the narrow marking on the object in (14a) should be preferred to the VP-level marking in (14b). We might look to question/answer pairs for guidance, but there we find the same distinction. Example (15) would suggest that Schwarzschild's theory should prefer narrow marking over broad marking:

(15) Q: Who did John's wife confront?

A: I don't know, but she IGNORED $\mathrm{JOHN}_{F} / \mathrm{HIM} \mathrm{M}_{F}$.

A': \# I don't know, but she [IGNORED $F$ John/him] $]_{F}$.

Note that the fact that A's response does not directly answer Q's question is irrelevant, since in Schwarzschild's analysis there is no special consideration for question/answer pairs beyond questions serving as possible antecedents. Example (16), however, suggests broad marking over narrow marking: 
(16) Q: What happened after John's wife confronted Sue?

A: She [DIVORCED $F$ him/John $]_{F}$.

$\mathrm{A}^{\prime}$ : \# She DIVORCED $F \mathrm{HIM}_{F} / \mathrm{JOHN}_{F}$.

Again we see the same alternation, since (15) exhibits the Resemblance relation Contrast, whereas (16) is an instance of the non-Resemblance relation Occasion.

This pattern is robust across a variety of configurations. Consider (17):

(17) $\{$ The student emailed the school board and $\}$

a. [they contacted [the POLICE] $\left.]_{F}\right]_{F} . \quad$ (they=the school board; Result)

b. THEY $F$ contacted [the POLICE] $F . \quad(T H E Y=$ the school board; Parallel)

If the school board contacted the police because of a threat in the student's email (i.e., a Result reading), the pronoun can be unaccented as in (17a). If the student and school board each contacted a respective authority to report some external event (i.e., a Parallel reading), the subject pronoun must be accented as in (17b).

In each of these minimal pairs, the different accent patterns are associated specifically with particular coherence construals. As such, treating the two F-markings as 'tied' does not help, since they cannot be freely interchanged. Furthermore, we have already encountered other cases in which AvoIDF makes a clear but erroneous prediction. Consider (6) again, repeated below as (18):

(18) \{Fred read the menu and then

a. \# he ORDERED $F$ [a HAMBURGER] $]_{F}$.

b. he $\left[\operatorname{ordered}_{F}[\mathrm{a} \mathrm{HAMBURGER}]_{F}\right]_{F}$.

AVOIDF predicts that (18a) is preferred over (18b) on analogy with the treatment of (8), which here is incorrect. Again, the difference between the two cases is that (8) is an instance of Contrast whereas (18) is an instance of Occasion.

Finally, example (19), a variant of Schwarzschild's example (63), shows a question/answer pair exhibiting the same alternation:

(19) \{What will they do if they fire the American president from the OSA?

a. They'll [hire $F$ the $\mathrm{FRENCH}_{F}$ President $_{F}$.

b. They'll HIRE $F$ the FRENCH $_{F}$ President.

Either follow-on is felicitous here, depending on whether the speaker wishes to contrast the antonyms hire and fire (per Contrast) or not. Such examples illustrate that utterances related by non-Resemblance (here, by a conditional) can at the same time be related by a form of Resemblance (as in (19b)). Schwarzschild's system again predicts that $(19 \mathrm{~b})$ would be strictly preferred. The same prediction would be made for verbs in the second clause that would not be so readily contrasted with fire and hence would not normally receive accent (e.g., recommend, contact, nominate). 
We have now seen a variety of examples for which a Resemblance construal requires one (typically more narrow) F-marking and a non-Resemblance construal requires another (typically more broad) F-marking. These facts suggest that Fmarking is not determined by an economy metric but instead by properties of the coherence construal itself. I explain why this would be the case in the next section.

\section{Coherence and the Background/Focus Partition}

The previous discussion demonstrated that any analysis of the facts at hand should not rely on economization of F-marking and should be sensitive to the influence of discourse coherence. In the two sections that follow, I discuss the differing ways in which Resemblance and non-Resemblance relations create a BACKGROUND/FOCUS partition for utterances that in turn affects accent placement. These properties eliminate the need for AVOIDF for predicting accentuation in these examples.

\subsection{Accent in Resemblance Relations}

In many ways the RESEMBLANCE category constitutes the special case, so I consider it first. The observation that accent patterns in these constructions are in some sense exceptional goes at least as far back as Chomsky (1971):

In 'parallel constructions', in some sense of this notion that has never been made quite clear, contrastive intonation is necessary. (Chomsky, 1971, p. 205)

In Kehler (2002) I cite six relations as belonging to the Resemblance category, but I will focus only on the Parallel relation here. (The Contrast relation that we have seen examples of is treated completely analogously.) Establishing Parallel requires the hearer to make the following inference for utterances $S_{1}$ and $S_{2}$ :

Parallel: Infer $p\left(a_{1}, a_{2}, \ldots\right)$ from the assertion of $S_{1}$ and $p\left(b_{1}, b_{2}, \ldots\right)$ from the assertion of $S_{2}$, where $a_{i}$ and $b_{i}$ are similar, for all $i$. (Hobbs 1990)

Examples of Parallel include (20a-d):

(20) a. George won the electoral vote, and $\mathrm{Al}$ won the popular vote.

b. John likes Bill, and Mary absolutely adores him.

c. Mary cleaned her room, and Sue read a book.

d. We have nothing to say to Ron Ziegler, and Al Haig's never been in politics. (Hobbs 1990)

Such passages are coherent in their having a COMMON TOPIC (in the sense of R. Lakoff (1971)) that serves as the background against which focal elements are introduced. For instance, the background for (20a) can be paraphrased as Which presidential candidates won which type of vote. (Example (20d), uttered by a reporter 
griping about poor press communications with the Nixon White House, shows that syntactic parallelism is unnecessary; Ron Ziegler and Al Haig are parallel elements despite occupying different grammatical roles.) Elements in the second clause that are not coreferential with their parallel elements in the first must be F-marked (and hence contain an accent) in such passages - regardless of their Givenness status in the remainder of the discourse - as they cannot be assimilated to the background. The resulting partition of the background and focus is captured by the Existential F-closures that we have considered for Parallel readings, which can be seen as impoverished representations of the 'common topic', unenriched with the semantic information used as a basis for establishing it.

These F-markings result directly from associating the mapping between parallel elements in Resemblance relations with one Schwarzschild uses in his formal of definition of Givenness. Space does not allow me to describe Schwarzschild's definition in detail, so I must refer the reader to section 2.2 of his paper. The point should come across however by considering his assignment function $h$ that assigns meanings to (indexed) F-markings:

a. If $\alpha$ is F-marked, then:

$\left[\left[[\alpha]_{F n}\right]\right]^{\mathrm{g}, \mathrm{h}}=\mathrm{h}(\mathrm{Fn})$

$\left[\left[[\alpha]_{F n}\right]\right]^{\mathrm{g}}=[[\alpha]]^{\mathrm{g}}$

b. If $\alpha$ has no F-marking, then:

$[[\alpha]]^{\mathrm{g}, \mathrm{h}}=[[\alpha]]^{\mathrm{g}}$ if $\alpha$ is not complex;

if $\alpha$ has components $\beta_{1} \ldots \beta_{n}$, then $[[\alpha]]^{\mathrm{g}, \mathrm{h}}$ is the result of applying the semantic rule for $\alpha$ to $\left[\left[\beta_{1}\right]\right]^{\mathrm{g}, \mathrm{h}} \ldots\left[\left[\beta_{n}\right]\right]^{\mathrm{g}, \mathrm{h}}$

Let us describe (21) in light of example (11), repeated below as (22a).
a. Powell defied Cheney, and Bush punished him.
b. BUSH $_{F_{1}}$ PUNISHED $F_{2}$ HIM $_{F_{3}}$. (Parallel; $H I M=$ Powell)
c. $\exists X \exists R \exists Y[X R$-ed $Y]$

If the pronoun him refers to Powell in (22a), the Parallel relation (and hence $h$ ) will enforce the following mapping:
a. $\left.\left[[\text { Bush }]_{F_{1}}\right]\right]^{g, h}=$ Powell
b. $\left.\left[[\text { [punished }]_{\mathrm{F}_{2}}\right]\right]^{\mathrm{g}, \mathrm{h}}=$ defied
c. $\left[\left[[\text { Powell }]_{\mathrm{F}_{3}}\right]\right]^{\mathrm{g}, \mathrm{h}}=$ Cheney

Because $h$ applies only to F-marked constituents per (21a), his must be F-marked for this mapping to hold, and by FOC must be accented despite it representing Given information. On the other hand, if him refers to Cheney, $h$ need not map it to a distinct entity per (21b) as it would then be coreferential with its parallel element. In this case the pronoun is not F-marked, $h$ only encodes (23a-b), and 
Cheney becomes part of the background (e.g., Who did what to Cheney). The facts therefore fall out naturally if we take the mapping that is used to establish Parallel to dictate the mapping incorporated in $h$ for establishing Givenness.

Although I have concentrated on cases that exhibit narrow F-marking, it is important to point out that the Parallel relation can apply to denotations at any level of constituency, which in tum provides further evidence that there can be no economy metric that is responsible for determining F-marking. Consider (24):

a. $\{$ What did the kids do this afternoon? $\}$

b. Mary cleaned her room, and $\mathrm{SUE}_{F}\left[\operatorname{read}_{F}[\mathrm{a} \mathrm{BOOK}]_{F}\right]_{F} .(=20 \mathrm{~b})$

Unlike the Parallel interpretation we considered for (22a), the VP-level predicates cleaned her room and read a book are parallel to one another, but their subcomponents are not, that is, there is no contrast intended between the verbs cleaned and read and between the noun phrases her room and $a$ book on the most natural interpretation. Hence the F-marking shown in (24b) and lack of accent on read. This relationship holds even though the source clause makes a transitive relation Given, thereby licensing narrow focus marking in Schwarzschild's system. Indeed, even (22a) can participate in VP-level parallelism in an appropriate context:

a. $\{$ What did folks do for fun today?

b. $\mathrm{DON}_{F}$ [gave $_{F}$ [a PRESS conference] $]_{F}$, POWELL $_{F}\left[\operatorname{defied}_{F} \mathrm{CHENEY}_{F}\right]_{F}, \mathrm{BUSH}_{F}\left[\operatorname{punished}_{F} \mathrm{POWELL}_{F}\right]_{F}$, $\mathrm{CONDI}_{F}\left[\right.$ played $_{F}\left[\text { the PIANO }_{F}\right]_{F} \ldots$

We would therefore not want a metric to choose between the F-markings (25) and (22b), as the key determinant is the level of parallelism intended to be recognized.

Finally, I conclude this section by addressing question/answer congruence in examples like (2), repeated below as (26).

a. $\left\{\right.$ Who did $\mathrm{John}_{j}$ 's mother praise?

b. She praised $\left[\mathrm{HIM}_{j}\right]_{F}$.

(Schwarzschild's ex. 11)

I believe such cases naturally fall into the Resemblance category, being based on establishing a mapping among parallel elements as we saw for Parallel. I would therefore treat (26) in the same way as the Parallel relation in (27), where the answer him is parallel to the Wh-form in (26) as opposed to Sue in (27).

a. $\left\{\mathrm{John}_{j}\right.$ 's mother praised Sue, and $\}$

b. she also praised $\left[\mathrm{HIM}_{j}\right]_{F}$.

In each case, the remainder of the elements in the second clause are coreferent with their parallel elements, and hence are not F-marked. This analysis appears to generate the same results as Schwarzschild's theory, without appeal to AvOIDF. 


\subsection{Accent in Non-Resemblance Relations}

In the last section, we saw that Resemblance relations such as Parallel are established by identifying a 'common topic' for a set of utterances. The resulting partition of the background and focus entails that a constituent will only be included as part of the background if it is coreferent with its parallel element. This manner of partitioning stands in contrast to non-Resemblance relations, which cohere by other means. One such means is cause-and-effect, as is manifest in the Result relation:

Result: Infer $P$ from the assertion of $S_{1}$ and $Q$ from the assertion of $S_{2}$, where normally $P \rightarrow Q$.

F-marking in such relations is not governed by a pairwise mapping since their definitions do not incorporate one. Instead, background information is more flexibly identified in non-Resemblance relations, with F-marking built around Given information with respect to the constituent structure of the sentence. Example (28a), for instance, has Result has its most natural interpretation:
a. John pushed Bill and he fell. (he=Bill)
b. $\operatorname{push}(J, B) \supset \operatorname{fall}(B)$

The cause-and-effect reading and the assignment of he to Bill are both licensed by the world knowledge that pushing someone can cause them to fall, schematically represented in (28b).

For the purpose of partitioning the background and focus, all that matters in this case is that the subject is Given and the predicate is New. Hence, unlike the examples discussed in section 4.1 , in (28) the pronoun does not receive accent even though it is neither syntactically nor semantically parallel to its antecedent. Instead, only fell is accented, in accordance with the following F-marking:

$[\mathrm{He} \mathrm{FELL}]_{F}$.

Here I follow Schwarzschild in F-marking the entire sentence (see also (17a)), since nothing in the discourse entails that Bill did something. On the other hand, Schwarzschild's system would presumably at least allow, if not prefer, the narrow F-marked version in (30) as well, since the first clause makes the Existential Fclosure for Someone did something Given:

$$
\mathrm{HE}_{F} \mathrm{FELL}_{F} \text {. }
$$

This F-marking erroneously predicts that accent on both he and fell would be felicitous on the relevant interpretation.

However, an interesting possibility arises if it were John that did the falling. In this case a speaker can felicitously accent he without accenting fell: 
This case is puzzling because the word that represents Given information receives accent whereas the one that represents New information does not. (Again, this fact is orthogonal to the decision to pronominalize; accent is still required if we replace he with John on the relevant Result reading.) A plausible analysis is that the presupposition of the Givenness of the Existential F-Closure of the second clause $\exists X . f e l l(X)$ - is being accommodated by virtue of the world knowledge expressed in (28b). That is, example (31) reads roughly as John pushed Bill, and as expected someone fell, but contrary to expectation it was John and not Bill who did. Assuming that the consequent of (28b) as instantiated by the first clause of (31) - fell(Bill) - is the inferred antecedent, (31) has the predicted F-marking. This analysis therefore suggests that this use of accent would be infelicitous without an expectation capable of giving rise to an inferrable antecedent, which appears to be correct:

\# John was talking to Bill and $\mathrm{HE}_{F}$ sat down.

Example (32) leaves the hearer searching for an interpretation because there is no expectation being violated on either pronoun assignment.

Let us now return to example (22a) with him assigned to Powell on the Result interpretation. In this case Powell is Given (and hence part of the background), and the subject and predicate are F-marked. As expected, we now find the accent pattern that is consistent with F-marking the VP, and without accent on the pronoun as licensed by (33b), as opposed to the narrow F-marking we found for the Parallel interpretation:

a. Powell defied Cheney, and BUSH ${ }_{F}$ PUUNISHED $_{F}$ him $]_{F}$.

b. $\operatorname{defy}(P, C) \supset \operatorname{punish}(B, P)$

As with (28), a speaker can create a contrast with expectation by accenting the pronoun and not accenting punish, generating the presupposition (on the relevant interpretation) that the punishment is predictable but the person who got punished is not (in light of 33b):

Powell defied Cheney, and $\mathrm{BUSH}_{F}$ punished $\mathrm{HIM}_{F}$.

To this point I have focused on examples of the Result relation, but the same facts hold true of other relations that are not in the Resemblance category. Example (6), repeated below as (35), is an example of the Occasion relation:

\{Fred read the menu and then

a. \# he ORDERED $F$ [a HAMBURGER $]_{F}$.

b. he $\left[\operatorname{ordered}_{F}[\text { a HAMBURGER }]_{F}\right]_{F}$. 
In this case there is no causality involved, just a connected sequence of events that center around a common system of entities. Again, F-marking is included on the VP in (35b), even though AVOIDF results in an unambiguous preference for (35a). And again, accent can be used to contrast with expectation:

(36) \{Fred summoned the bartender and then

a. he $\left[\operatorname{ordered}_{F}[\mathrm{a} \mathrm{DRINK}]_{F}\right]_{F}$.

b. $\mathrm{HE}_{F}$ ordered a drink. $\quad(H E=$ bartender $)$

Although world knowledge is again necessary to license a presupposition here as it was in (31), (36b) shows that this knowledge need not be causal in nature.

A final clarification is in order with respect to the F-markings I have posited in this section. The attentive reader will note that $\mathrm{I}$ have not included F-markings at the sentence level for any examples except (28), as shown in (29). While this is expected in Schwarzschild's system - in all cases but (28) the Existential F-closure of the sentence was already Given - there is nothing that prohibits sentence-level F-marking if we are no longer appealing to AvoIDF. Indeed, it is just this type of additional F-marking that I have argued exists on the VP of (35b), one of my central motivations for dispensing with AvOIDF. As we saw in that case, adding a new F-marker can change the predicted accent patterns. In Schwarzschild's analysis, adding sentence-level F-marking to examples with an F-marked subject and predicate such as (33a) would have the same effect.

It is not clear that it should, however. As noted by Selkirk (1996) for related examples, George requires accent in a passage such as (37) if he is New:
a. $\{$ It is raining, and so $\}$
b. $\left[\mathrm{GEORGE}_{F}\left[\operatorname{got}_{F}[\operatorname{an} \mathrm{UMBRELLA}]_{F}\right]_{F}\right]_{F}$

While nothing in Schwarzschild's system prohibits this accent (indeed, this is a case in which economy of F-marking has no implications for economy of accent), nothing requires it either. Since everything in (37b) is F-marked, only the sentence is Foc-marked, and thus having only an accent on umbrella is enough to satisfy FOC. As such, if sentential F-marking were included on the foregoing examples, it appears that we may still want an analysis that requires the same accent patterns that would be predicted by Schwarzschild's analysis without sentential F-marking. Conversely, the sentential F-marking on (29) can be eliminated without impacting the predicted accent pattern. At this point I leave the issue for further study.

\subsection{Avoiding AvOIDF}

To summarize to this point, a variety of facts argue against the existence of a constraint akin to AvOIDF that governs accent placement in English. For some examples, an economy metric cannot discriminate competing F-markings that are tied to particular coherence construals, whereas for others, F-marking economization generates a clear preference for an infelicitous accent pattern. Instead, F-marking 
is in part determined by the coherence construal that the speaker intends the hearer to recognize, specifically in terms of how this construal partitions the background and focus components of an utterance. This fact eliminates the need for AVOIDF's primary function in these examples, which is to ban superfluous F-marking.

AvoIDF serves a second and less direct function as well, however, which is to conspire with the Basic Focus Rule to implement a particular type of 'deaccenting' (à la Ladd (1980)). As we saw for example (7), in a case in which a head represents New information and an internal argument represents Given information, the additional F-marking that would be required to accent the argument will run afoul of AVOIDF; since AVOIDF outranks HEADARG, accent on the head is preferred. As we have seen, however, there is no deaccenting effect in Resemblance structures; in particular the accent on the verb in (22) does not allow its pronominal direct object to escape accent even though it represents Given information (note also the lack of deaccenting in the F-marked VP of the third clause of (25b), where again Powell is not part of the background). Furthermore, the deaccenting effect results naturally in non-Resemblance relations, since a direct object that is Given will effectively be assimilated to the background when the verb is New. Only in those cases in which a Given object combines with a Given verb to form a New VP will the object receive accent (e.g., John yelled at Sue and so she/SHE yelled at HIM). This fact is successfully predicted by HEADARG alone; in particular AVOIDF plays no role since accenting either the verb or object would require an additional F-mark. Otherwise, only the mapping established in Resemblance relations (as well as for inferred antecedents in the violated expectation examples we have considered) will cause a Given constituent to be F-marked under appropriate circumstances.

\section{Relationship to QUD Models}

The analysis just described has properties in common with the QUESTION UNDER DISCUSSION (QUD) approach proposed by Roberts (1996) and subsequently taken up by Buring (2003). Both have a richer infrastructure than Schwarzschild's approach, being based at some level on the interplay among focus, accent, presupposition, and discourse coherence.

Despite these similarities, I believe that the richer, knowledge-driven infrastructure brought by a theory of informational coherence is ultimately necessary to predict accent pattems in discourse. For instance, while the QUD model offers an intuitive treatment of examples involving Parallel relations as providing answers to an implicit (multi-)Wh question - in the sense that (11) provides a joint answer to the inferred question Who did what? on its Parallel interpretation - it must be explained why the same accent pattern seems unnatural for examples like (6) outside of an exceptional context, which could otherwise be understood to answer a similar question (i.e., what did Fred do to what?). Intuitively it is information-level coherence establishment processes - in ways that no doubt remain poorly understood - that lead to the different coherence construals for (11) and (6). As I have argued elsewhere (Kehler 2004), from an interpretation standpoint coherence estab- 
lishment seems to be necessary in order to identify the implicit QUD of a passage post-hoc, perhaps rendering the latter an epiphenomenal notion.

A similar point applies to the examples we have considered in the Result category. Recall our earlier examples (28) and (31), repeated here as (38a-b):
a. John pushed Bill and [he FELL $]_{F}$.
(he=Bill)
b. John pushed Bill and $\mathrm{HE}_{F}$ fell.
$(H E=\mathrm{John})$

As these are both instances of Result, the QUDs for the second clauses are presumably the same, along the lines of And what happened as a result?. It is only world knowledge that tells us what the expected role fillers are, i.e., that usually the person who was pushed is the one who falls (thereby not requiring accent on he in (38a)) rather than the one who did the pushing (thereby requiring accent on he in (38b)). Again, coherence establishment seems necessary to determine what both the QUD and accent patterns are.

Finally, although accent patterns have been shown to vary across the different coherence construals for examples like (11), in many cases different construals result in the same distribution of accent. Consider (39a-b):

a. Sue voted for Bush, and likewise $\mathrm{MARY}_{F}$ voted for him.

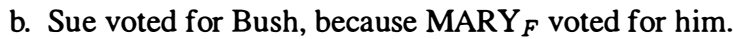

The Parallel construction in (39a) is naturally understood to provide a joint answer to an implicit QUD akin to Who voted for Bush?. On the other hand, the QUD for the second clause of (39b) is presumably Why?, in light of the connective because. This accent pattern is unexpected as a response tailored solely to this QUD, which corresponds to a focus alternative set containing all propositions. Accent patterns remain sensitive to antecedents in the discourse (and not just QUDs) for all types of coherence. The analysis I have offered here assimilates the VP in both of (39a-b) to their respective backgrounds, predicting the lack of accent in each case.

\section{Gapping and Coherence}

I have so far described facts concerning a variety of focus/accent constellations in simple intransitive and transitive clauses. One case I have not described is where a transitive clause combines a Given verb with a New subject and object. Such cases are candidates for deletion of the verb, resulting in a gapping construction.

As originally pointed out by Levin and Prince (1986, henceforth L\&P), and discussed at some length in Kehler (2002), gapping the verb in such clauses constrains the coherence construals that would otherwise be available. Specifically, whereas L\&P's passages (40a-c) each display an ambiguity between Parallel and Result construals, their corresponding gapped versions in (41a-c) only have a Parallel interpretation. 
(40) a. Sue became upset and Nan became downright angry.

b. Al cleaned up the bathroom and Joe cleaned up the mess.

c. One of the students was accepted at Bryn Mawr and the high school was praised on TV.

(41) a. Sue became upset and Nan $\emptyset$ downright angry.

b. Al cleaned up the bathroom and Joe $\emptyset$ the mess.

c. One of the students was accepted at Bryn Mawr and the high school $\emptyset$ praised on TV.

Utilizing the ORDERED ENTAILMENT framework of Wilson and Sperber (1979), L\&P posit a DISCOURSE FUNCTION OF GAPPING rule that stipulates that clauses in a gapped structure share FIRST BACKGROUND ENTAILMENTS that are analogous to the Existential F-closures for the Parallel examples we have considered. Parallel relations (or 'symmetric' readings in their terms) are claimed to have this property, whereas Result relations (or 'asymmetric' readings) are claimed not to.

The account I have presented here reproduces the spirit of their analysis from independent principles provided that we adopt a ban on the elision of focal material. That is, while the same lexical items receive accent for the two readings of (40a), their F-markings are different under the current analysis:

(42) Sue became upset and $\mathrm{NAN}_{F}$ became [DOWNRIGHT ANGRY] . $_{\text {. }}$ (Parallel)

(43) Sue became upset and $\mathrm{NAN}_{F}$ [became [DOWNRIGHT ANGRY] $]_{F}$. (Result)

As such, the verb became, while not accented in either case, is still part of a focal constituent in (43) whereas it is not in (42). While it is commonly assumed that accented material cannot be felicitously deleted (for the obvious reason that deleted material cannot carry accent), these facts suggest the constraint may be informationstructural, applying to unaccented focal material as well.

Having offered this speculative observation, I want to stress that there are more constraints at play in gapping that those just noted. Indeed, in Kehler (2002) I posited an analysis in which the aforementioned pattern falls out as a result of a syntactic reconstruction process that is only triggered for the Parallel interpretation. Hendriks (2004) criticizes this account, stating that the ability to gap "does not lie in the (im)possibility to reconstruct the missing material", but is instead due to the fact that "ellipsis processes differ in their relation to the topic of the sentence" (p. 133). In making her case, however, she does not address evidence that caused me to augment my pragmatic analysis with a reconstruction component, including the existence of binding theory violations that are only expected on a syntactic approach. While I am sympathetic to the desire for a purely information-structural analysis, an explanation of how these facts can be accounted for is still necessary. 
Furthermore, Hendriks takes it as a given that "gapping requires the remnants to bear contrastive stress", which she then claims "explains why the gapped sentence [(41a)] only has a symmetric reading" (p. 142). The restriction that parallel elements in the source and gapped clauses require complex 'contrastive' accents which I, following Sag (1976), echoed in Kehler (2002) but am no longer convinced is always witnessed - is in any case a fact that should be explained rather than assumed. While Hendriks and I agree that the complex accents characteristic of Parallel relations are felicitous for examples like (42), her analysis does not offer an explanation for why a gapped version of (43) would not be felicitous with simple high pitch accents on the subject and object of the second clause, whereas the constraint that I have (admittedly speculatively) suggested here does.

\section{Conclusion}

In this paper I have argued that felicitous accent patterns cannot be definitively determined by a economy criterion on F-marking in Schwarzschild's sense. We have seen passages in which an economy metric cannot discriminate competing F-markings that are tied to particular coherence construals, and well as others in which any rational metric would generate an unambiguous preference for an infelicitous accent pattern. I have claimed that the manner in which different coherence relations partition background and focus eliminates the need for this constraint for the class of examples discussed here. Further work will be required, however, to determine the extent to which the same result can be achieved on a broader range of data.

I have spoken in terms of 'coherence relations' like Parallel and Result as being atomic notions that in part determine information structure. But we have also made some progress toward breaking these down into more primitive notions, such as 'intonational anaphora', accommodation of both 'common topics' and causal 'inferrable' relationships, and the interaction of these with world knowledge. The interpretive richness we ascribe to coherence could ultimately turn out to be a purely emergent phenomenon, arising out of a speaker's use of basic linguistic tools (e.g., intonation) to manage the hearer's use of world knowledge and inference during discourse comprehension. A better understanding of this interaction holds considerable promise for ultimately explaining the quite complex empirical facts regarding a variety of discourse-dependent linguistic phenomena, including pronoun and ellipsis interpretation.

\section{Endnotes}

* Many thanks to Amalia Arvaniti, Chris Barker, David Beaver, Mark Gawron, Roger Schwarzschild, Michael Wagner, and the students in my Spring 2005 Topics in Pragmatics seminar at UCSD for helpful discussions. 


\section{References}

Büring, Daniel: 2003, 'On D-Trees, Beans, and B-Accents', Linguistics and Philosophy, 26, 511-545.

Chomsky, Noam: 1971, 'Deep Structure, Surface Structure, and Semantic Interpretation', in D. Steinberg and L. Jakobovits (eds.) Semantics: An Interdisciplinary Reader in Philosophy, Linguistics, and Psychology, Cambridge University Press, Cambridge, 183-216.

D. Robert Ladd, Jr.: 1980, The Structure of Intonational Meaning, Indiana University Press, Bloomington.

Halliday, M.A.K.: 1967, 'Notes on Transitivity and Theme in English (Part 2)', Journal of Linguistics, 3, 199-244.

Hendriks, Petra: 2004, 'Coherence Relations, Ellipsis and Contrastive Topics', Journal of Semantics, 21, 133-153.

Hobbs, Jerry R: 1990, Literature and Cognition, CSLI Lecture Notes 21, Stanford, CA.

Kehler, Andrew: 2002, Coherence, Reference, and the Theory of Grammar, CSLI Publications.

Kehler, Andrew: 2004, 'Discourse Topics, Sentence Topics, and Coherence', Theoretical Linguistics, 30, 227-240.

Krifka, Manfred: 2004, 'The Semantics of Questions and the Focusation of Answers', in Chungmin Lee, Matthew Gordon, and Daniel Büring (eds.) Topic and Focus: A Cross-Linguistic Perspective, Kluwer Academic Publishers, Dordrecht, 139-151.

Lakoff, Robin: 1971, 'If's, And's, and But's about Conjunction', in Charles J. Fillmore and D. Terence Langendoen (eds.) Studies in Linguistic Semantics, Holt, Rinehart, and Winston, New York, 114-149.

Levin, Nancy and Ellen F. Prince: 1986, 'Gapping and Causal Implicature', $\mathrm{Pa}$ pers in Linguistics, 19, 351-364.

Roberts, Craige: 1996, 'Information Structure in Discourse: Towards and Integrated Formal Theory of Pragmatics', In J. H. Yoon and Andreas Kathol (eds.) OSU Working Papers in Linguistics 49: Papers in Semantics, 91-136.

Sag, Ivan: 1976, Deletion and Logical Form, Ph.D. thesis, Massachusetts Institute of Technology.

Schwarzschild, Roger: 1999, 'Givenness, AvoidF, and Other Constraints on the Placement of Accent', Natural Language Semantics, 7, 141-177.

Selkirk, Elisabeth O.: 1996, 'Sentence Prosody: Intonation, Stress and Phrasing', in John A. Goldsmith (ed.) The Handbook of Phonological Theory, Blackwell, London.

Wilson, Deirdre and Dan Sperber: 1979, 'Ordered Entailments: An Alternative to Presuppositional Theories', in C. K. Oh and D. Dinneen (eds.) Syntax and Semantics XI: Presupposition, Academic Press, 299-323. 